OPEN ACCESS

Edited by:

Weiwen Zhang,

Tianjin University, China

Reviewed by:

Amy Michele Grunden,

North Carolina State University, USA

Fu-Li Li,

Qingdao Institute of Bioenergy and Bioprocess Technology (CAS), China Jesus Colprim,

Universitat de Girona, Spain

*Correspondence:

Largus T. Angenent

I.angenent@uni-tuebingen.de

${ }^{\dagger}$ These authors have contributed equally to this work

Specialty section:

This article was submitted to Microbiotechnology, Ecotoxicology and Bioremediation,

a section of the journal

Frontiers in Microbiology

Received: 17 June 2016

Accepted: 21 October 2016

Published: 08 November 2016

Citation:

Richter H, Molitor B, Diender M, Sousa DZ and Angenent LT (2016) A Narrow pH Range Supports Butanol, Hexanol, and Octanol Production from Syngas in a Continuous Co-culture of Clostridium ljungdahlii and Clostridium kluyveri with In-Line Product Extraction. Front. Microbiol. 7:1773. doi: 10.3389/fmicb.2016.01773

\section{A Narrow pH Range Supports Butanol, Hexanol, and Octanol Production from Syngas in a Continuous Co-culture of Clostridium ljungdahlii and Clostridium kluyveri with In-Line Product Extraction}

\author{
Hanno Richter ${ }^{1 \dagger}$, Bastian Molitor ${ }^{1 \dagger}$, Martijn Diender ${ }^{2}$, Diana Z. Sousa ${ }^{2}$ and \\ Largus T. Angenent ${ }^{1,3 *}$
}

\footnotetext{
${ }^{1}$ Department for Biological and Environmental Engineering, Cornell University, Ithaca, NY, USA, ${ }^{2}$ Laboratory of Microbiology, Wageningen University, Wageningen, Netherlands, ${ }^{3}$ Atkinson Center for a Sustainable Future, Cornell University, Ithaca, NY, USA
}

Carboxydotrophic bacteria (CTB) have received attention due to their ability to synthesize commodity chemicals from producer gas and synthesis gas (syngas). CTB have an important advantage of a high product selectivity compared to chemical catalysts. However, the product spectrum of wild-type CTB is narrow. Our objective was to investigate whether a strategy of combining two wild-type bacterial strains into a single, continuously fed bioprocessing step would be promising to broaden the product spectrum. Here, we have operated a syngas-fermentation process with Clostridium ljungdahlii and Clostridium kluyveri with in-line product extraction through gas stripping and product condensing within the syngas recirculation line. The main products from C. ljungdahlii fermentation at a $\mathrm{pH}$ of 6.0 were ethanol and acetate at net volumetric production rates of 65.5 and $431 \mathrm{mmol} \mathrm{C} \cdot \mathrm{L}^{-1} \cdot \mathrm{d}^{-1}$, respectively. An estimated 2/3 of total ethanol produced was utilized by $C$. kluyveri to chain elongate with the reverse $\beta$-oxidation pathway, resulting in $n$-butyrate and $n$-caproate at net rates of 129 and 70 mmol $C \cdot L^{-1} \cdot d^{-1}$, respectively. C. ljungdahlii likely reduced the produced carboxylates to their corresponding alcohols with the reductive power from syngas. This resulted in the longer-chain alcohols $n$-butanol, $n$-hexanol, and $n$-octanol at net volumetric production rates of $39.2,31.7$, and $0.045 \mathrm{mmol} C \cdot \mathrm{L}^{-1} \cdot \mathrm{d}^{-1}$, respectively. The continuous production of the longer-chain alcohols occurred only within a narrow pH spectrum of 5.7-6.4 due to the $\mathrm{pH}$ discrepancy between the two strains. Regardless whether other wild-type strains could overcome this $\mathrm{pH}$ discrepancy, the specificity (mol carbon in product per mol carbon in all other liquid products) for each longer-chain alcohol may never be high in a single bioprocessing step. This, because two bioprocesses compete for intermediates (i.e., carboxylates): (1) chain elongation; and (2) biological reduction. This innate competition resulted in a mixture of $n$-butanol and $n$-hexanol with traces of $n$-octanol.

Keywords: alcohol, hexanol, octanol, syngas, Clostridium ljungdahlii, Clostridium kluyveri, co-culture 


\section{INTRODUCTION}

Depletion of fossil energy carriers and concomitant emissions of greenhouse gases has stimulated research and development of energy systems that are sustainable and carbon neutral. One avenue, besides wind, solar, and hydroelectric power, is the conversion of producer gas into chemicals and fuels (Daniell et al., 2016). Producer gas can come from industrial off gases from the steelmaking industry or from gasification of solid organic waste streams (biomass and municipal waste; Munasinghe and Khanal, 2010; Molitor et al., 2016). Producer gas, which we refer to as syngas, is composed of mainly carbon monoxide $(\mathrm{CO})$, hydrogen $\left(\mathrm{H}_{2}\right)$, and carbon dioxide $\left(\mathrm{CO}_{2}\right)$, with nitrogen, methane, and other compounds at lower concentrations. Recovery of carbon from syngas is a potential strategy to reduce consumption of fossil energy carriers and to reduce greenhouse gas emissions (Dürre, 2016).

Biological conversion of syngas with carboxydotrophic bacteria (CTB) is currently receiving attention because of the technology transfer to industrial scales at steel mills (Liew et al., 2016; Molitor et al., 2016). Specifically, Clostridium ljungdahlii and Clostridium autoethanogenum produce ethanol using either $\mathrm{CO}$ or $\mathrm{H}_{2}$ and $\mathrm{CO}_{2}$ as substrates (Mock et al., 2015). Bioprocesses with CTB operate at ambient temperatures and pressures, which is an advantage compared to using metal catalysis to convert syngas into chemicals and fuels (Molitor et al., 2016). In addition, CTB are specific in their product portfolio, and have been suggested to tolerate gas contaminants and fluctuating $\mathrm{H}_{2} / \mathrm{CO}$ ratios better than metal catalysts (Dry, 2002; Liew et al., 2013). The spectrum of useful products from wild-type CTB is narrow with ethanol, 2,3-butanediol, and acetate as the only products that can be produced at a promising selectivity (mol carbon in product per mol carbon in substrate). The environmental conditions determine which of these products are being produced based on thermodynamics rather than genetic control between acidogenesis and solventogenesis (Richter et al., 2016). Some CTB, such as C. carboxidivorans $\mathrm{P} 7$, also produce $n$-butanol and $n$-hexanol from syngas, however, the achieved production rates and selectivities are low (Bruant et al., 2010; Ramió-Pujol et al., 2015).

At least four different biological strategies have already been used to broaden the product spectrum of syngas fermentation: (1) genetic modification in a pure culture, single bioprocessing step; (2) coupling several separate bioprocessing steps; (3) culturing two or more pure culture strains in a single bioprocessing step; and (4) using an undefined mixed culture (reactor microbiome) in a single bioprocessing step. For the first strategy, genetic modification has already resulted in strains that can produce n-butyrate (Ueki et al., 2014), n-butanol (Köpke et al., 2010), isopropanol (Köpke et al., 2012), and acetone (Banerjee et al., 2014). With the development of reliable and less labor-intense molecular biological tools for CTB, the product spectrum is likely to be further increased (Walker and Köpke, 2015; Huang et al., 2016). The successful demonstration of the functionality of CRISPR/Cas9 systems in relevant CTB is promising to lead to a considerable increase in the number of genetically modified strains (Wang et al., 2015; Xu et al., 2015; Huang et al., 2016).

For the second strategy, Vasudevan et al. (2014) had fed syngas fermentation broth with ethanol and acetate from a pureculture of C. ljungdahlii to an anaerobic reactor microbiome at mildly acidic $\mathrm{pH}$ levels. Because of the inhibition of acetoclastic methanogens at that $\mathrm{pH}$, the syngas fermentation products ethanol and acetate were chain elongated to $n$-butyrate and $n$ caproate (Vasudevan et al., 2014). Recently, this strategy was further improved by producing mostly $n$-caprylate (Kucek et al., 2016). The chain elongation mechanism via the reverse $\beta$ oxidation pathway has been well described in the literature for Clostridium kluyveri (Seedorf et al., 2008; Spirito et al., 2014). Chain elongation of the acetate carbon backbone (C2) with ethanol (C2) as an electron donor, energy source, and source of carbon results in $n$-butyrate (C4), n-caproate (C6), and $n$-caprylate (C8). We refer to the last two products as medium-chain carboxylates (MCCs). This microbial pathway generates ATP by producing more reduced products than acetate (Hanselmann, 1991; Kleerebezem and Van Loosdrecht, 2010; Agler et al., 2014; Angenent et al., 2016). The reversed order of the set-up for the two bioprocessing steps was also investigated within a biorefinery concept that combined three separate platform technologies - sugar, carboxylate, and syngas platforms (Richter et al., 2013a). Within that concept, syngas fermentation was placed after chain elongation rather than before to reduce non-extracted carboxylates into their corresponding alcohols. Previous work had already described the reduction of carboxylates into their corresponding alcohols by wild-type CTB during syngas fermentation in a single bioprocess (Perez et al., 2013). Finally, two bioprocessing steps in series combined syngas fermentation with aerobic yeast production to convert acetate into malic acid (Oswald et al., 2016) or C16 and C18 lipids (Hu et al., 2016).

For the third strategy, a co-culture of C. autoethanogenum and C. kluyveri converted syngas into MCCs and longer-chain alcohols in batch fermentations (Diender et al., 2016). This coculture produced $n$-butanol $\left(14 \mathrm{mmol} \mathrm{C} \cdot \mathrm{L}^{-1} \cdot \mathrm{d}^{-1}\right), n$-hexanol (12 mmol C $\left.\cdot \mathrm{L}^{-1} \cdot \mathrm{d}^{-1}\right), n$-butyrate $\left(41.6 \mathrm{mmol} \mathrm{C} \cdot \mathrm{L}^{-1} \cdot \mathrm{d}^{-1}\right)$, and $n$ caproate $\left(17.4 \mathrm{mmol} \mathrm{C} \cdot \mathrm{L}^{-1} \cdot \mathrm{d}^{-1}\right)$, besides ethanol and acetate. In these batch fermentations, Diender et al. did not observe products with a carbon chain longer than C6. Besides the production of $n$-butyrate and $n$-caproate from chain elongation, Diender et al. observed the reduction of these carboxylates to $n$-butanol and $n$-hexanol. From previous work by Perez et al. (2013), it seems most plausible that C. autoethanogenum reduced the elongated products (i.e., carboxylates) from C. kluyveri to the corresponding alcohols in a final pathway. The reduction of carboxylates by C. kluyveri cannot be ruled out, however, especially since small amounts of $n$-hexanol were found as a fermentation product in pure culture fermentations with $C$. kluyveri (Barker and Taha, 1942; Thauer et al., 1968; Kenealy and Waselefsky, 1985; Weimer and Stevenson, 2012). The co-culture with $C$. autoethanogenum and $C$. kluyveri was only functional in a $\mathrm{pH}$ range from 5.5 to 6.5 and an increase in the $\mathrm{pH}$ at the end of the fermentation was a limiting factor for the batch fermentation. A well-established C. autoethanogenum culture 
that consumed $\mathrm{CO}$ was critical to avoid toxic effects of the $\mathrm{CO}$ on C. kluyveri when the co-culture was incubated with shaking for better gas-liquid mass-transfer (Diender et al., 2016).

For the fourth strategy, Ganigué et al. (2016) used an acclimated reactor microbiome to produce varying mixtures of $n$-butanol, $n$-hexanol, $n$-butyrate, and $n$-caproate from syngas during batch fermentations. The main products consisted of ethanol and $n$-butanol with only small quantities of products that were longer than C4. There are many similarities in the microbial pathways that are present when compared to the coculture study of Diender et al. (2016). However, the production rates with the reactor microbiome were approximately 10 -fold lower compared to the defined co-culture: $n$-butanol $(2.7 \mathrm{mmol}$ $\left.\mathrm{C} \cdot \mathrm{L}^{-1} \cdot \mathrm{d}^{-1}\right)$ and $n$-hexanol $\left(1.6 \mathrm{mmol} \mathrm{C} \cdot \mathrm{L}^{-1} \cdot \mathrm{d}^{-1}\right)$. Ganigué et al. (2016) found that the $\mathrm{pH}$ level in the batch fermenter was of utmost importance for productivity in the single bioprocess step. Unfortunately, a discrepancy in optimum $\mathrm{pH}$ levels between ethanol production with CTB and chain elongation with chainelongating bacteria, such as C. kluyveri, was observed. Ethanol production with CTB is optimal at a mildly acidic $\mathrm{pH}$ level of 4.55.5 (Worden et al., 1991; Mohammadi et al., 2011). For example, ethanol production has been observed at $\mathrm{pH} 5.3$ in a single-stage bioreactor with optimum growth (Mock et al., 2015). On the contrary, chain elongation to $n$-caproate or $n$-caprylate without product extraction is optimal at a neutral $\mathrm{pH}$ level of 6.5-7.5 (Grootscholten et al., 2013). Chain elongation was considerably inhibited at mildly acidic conditions due to the high toxicity of undissociated medium-chain carboxylic acids ( $\mathrm{pKa} \sim 4.9$ ) (Spirito et al., 2014).

The third and fourth strategies used batch fermentation. However, a continuous fermentation system with in-line product extraction is advantageous for an industrial-scale biotechnology production platform, because it leads to less downtime within the process due to continuous production. Therefore, our initial objective was to convert the single bioprocess step from a batch system into a continuous system and to add gas stripping to investigate whether we could generate a broader product spectrum for syngas fermentation by integrating two biological processes into a single bioprocessing step, and optimizing production rates by removing toxic end products. Because of the higher production rates of the defined co-culture compared to the undefined mixed culture (Diender et al., 2016; Ganigué et al., 2016), and due to C. ljungdahlii's excellent ethanol production rates (Martin et al., 2015), we chose another co-culture with C. ljungdahlii and C. kluyveri in a single bioprocessing step. In our co-culture, C. ljungdahlii fermented syngas into acetate and ethanol. These products were used as substrates by C. kluyveri to chain-elongate them into longer-chain carboxylates. Further, biological reduction of these carboxylates led to the production of longer-chain alcohols. The last step was most likely catalyzed by C. ljungdahlii. At a narrow $\mathrm{pH}$ range, we observed longerchain alcohols, consisting of mostly $n$-butanol and $n$-hexanol with some $n$-octanol. We aimed at increasing the production rates compared to the previous batch-fermentations (Diender et al., 2016). However, the production rates and specificities for each alcohol remained suboptimal and further optimization is needed.

\section{MATERIALS AND METHODS}

\section{Microbial Strains and Medium Composition}

Clostridium ljungdahlii strain PETC and Clostridium kluyveri strain DSM555 were obtained from ATCC (Manassas, VA). For pre-culturing, C. ljungdahlii was routinely grown in modified P7 medium in $160 \mathrm{~mL}$ serum bottles with a working volume of $10 \mathrm{~mL}$ at $35^{\circ} \mathrm{C}$ under a syngas headspace (Richter et al., 2013b), and C. kluyveri was grown in DSMZ52 medium in 160 $\mathrm{mL}$ serum bottles with a working volume of 20 or $50 \mathrm{~mL}$ at $35^{\circ} \mathrm{C}$ under strictly anaerobic conditions without shaking. For the reactor study, we used a medium almost identical to a previously described mineral medium with $2 x$ concentrations of all components compared to the described medium (Mock et al., 2015): (1) $60 \mathrm{~mL}$ of mineral salt solution $\left(4 \mathrm{~g} \mathrm{NaCl}, 100 \mathrm{~g} \mathrm{NH}_{4} \mathrm{Cl}\right.$, $5 \mathrm{~g} \mathrm{KCl}, 27.23 \mathrm{~g} \mathrm{KH}_{2} \mathrm{PO}_{4}, 13.33 \mathrm{~g} \mathrm{MgCl}_{2} \times 6 \mathrm{H}_{2} \mathrm{O}$, and $9.8 \mathrm{~g}$ $\mathrm{CaCl}_{2}$ per L); (2) $20 \mathrm{~mL}$ of vitamin solution [10 $\mathrm{mg}$ pyridoxinehydrochloride, $50 \mathrm{mg}$ thiamine, $50 \mathrm{mg}$ riboflavin, $50 \mathrm{mg}$ calcium pantothenate, $50 \mathrm{mg}$ thioctic acid, $50 \mathrm{mg}$-aminobenzoic acid, $50 \mathrm{mg}$ nicotinic acid, $50 \mathrm{mg}$ vitamin $\mathrm{B}_{12}, 20 \mathrm{mg}$ biotin, $20 \mathrm{mg}$ folic acid, and $10 \mathrm{mg}$ Mesna (Mercaptoethanesulfonic acid sodium salt) per L]; and (3) $20 \mathrm{~mL}$ of trace element solution [2 g NTA (nitrilotriacetic acid), $25.2 \mathrm{mg} \mathrm{MgCl}_{2}, 2.84 \mathrm{~g}\left(\mathrm{NH}_{4}\right)_{2} \mathrm{Fe}\left(\mathrm{SO}_{4}\right)_{2}$, $47.6 \mathrm{mg} \mathrm{CoCl}_{2}, 200 \mathrm{mg} \mathrm{ZnSO}_{4} \times 7 \mathrm{H}_{2} \mathrm{O}, 119 \mathrm{mg} \mathrm{NiCl} 2 \times 6 \mathrm{H}_{2} \mathrm{O}$, $48.4 \mathrm{mg} \mathrm{Na} \mathrm{MoO}_{4}, 34.6 \mathrm{mg} \mathrm{Na} \mathrm{SeO}_{3}$, and $66 \mathrm{mg} \mathrm{Na}_{2} \mathrm{WO}_{4} \times 2$ $\mathrm{H}_{2} \mathrm{O}$ per L]. We added 5 to $20 \mathrm{~mL}$ of $100 \times$ diluted antifoam 204 (Sigma Aldrich, St. Louis, MO) per L medium depending on the density of the bacterial culture in the reactor. We also added 1 $\mathrm{mM}$ final concentration of cysteine after sparging the medium with $\mathrm{N}_{2}$ gas to obtain anaerobic conditions. Finally, we added $0.8 \mathrm{~mL}$ sodium sulfide per $\mathrm{h}$ from an anaerobic $100 \mathrm{mM}$ stock solution directly to the $1 \mathrm{~L}$ reactor to continuously supply $\mathrm{H}_{2} \mathrm{~S}$ as an additional sulfur source. This resulted in an apparent $\mathrm{H}_{2} \mathrm{~S}$ concentration of $1 \mathrm{mM}$ at a media flow rate of $80 \mathrm{~mL} \cdot \mathrm{h}^{-1}$ (until hour 1150), and $2 \mathrm{mM}$ after we reduced the media flow rate to 40 $\mathrm{mL} \cdot \mathrm{h}^{-1}$ on hour 1150 .

\section{Reactor and Condenser Setup}

One $2 \mathrm{~L}$ Biostat $\mathrm{M}$ chemostat (Braun, Allentown, PA) with a $1 \mathrm{~L}$ working volume was used for the reactor experiment (Figure 1). The reactor was initially agitated at $200 \mathrm{rpm}$ (until hour 475), which was then increased to $400 \mathrm{rpm}$. The temperature was controlled at $37^{\circ} \mathrm{C}$ by a water jacket. The $\mathrm{pH}$ in the reactor was initially only controlled by addition of $2 \mathrm{M} \mathrm{KOH}$ (until hour 1510), and then also controlled by addition of $2 \mathrm{M}$ acetic acid (after hour 1510). The reactor was continuously supplied with a synthetic syngas mixture consisting of $60 \%$ ( $\mathrm{vol} / \mathrm{vol}$ ) $\mathrm{CO}, 35 \% \mathrm{H}_{2}$, and $5 \% \mathrm{CO}_{2}$ (Airgas East, Ithaca, NY) at a gas flow rate of $30-$ $80 \mathrm{~mL} \cdot \mathrm{min}^{-1}$ (the gas flow rate was adjusted, before gas supply became limiting) into the headspace of the reactor. The gas composition resembles the composition of syngas that is derived from lignocellulosic biomass with gasification such as with plasma gasification. A real producer gas should be tested before full-scale implementation to understand the effect of impurities on the co-culture behavior (Molitor et al., 2016). In addition, the gas was recycled at a gas flow rate of $1.6 \mathrm{~L} \cdot \mathrm{min}^{-1}$ (Figure 1). The recycled gas was sparged into the reactor broth through 


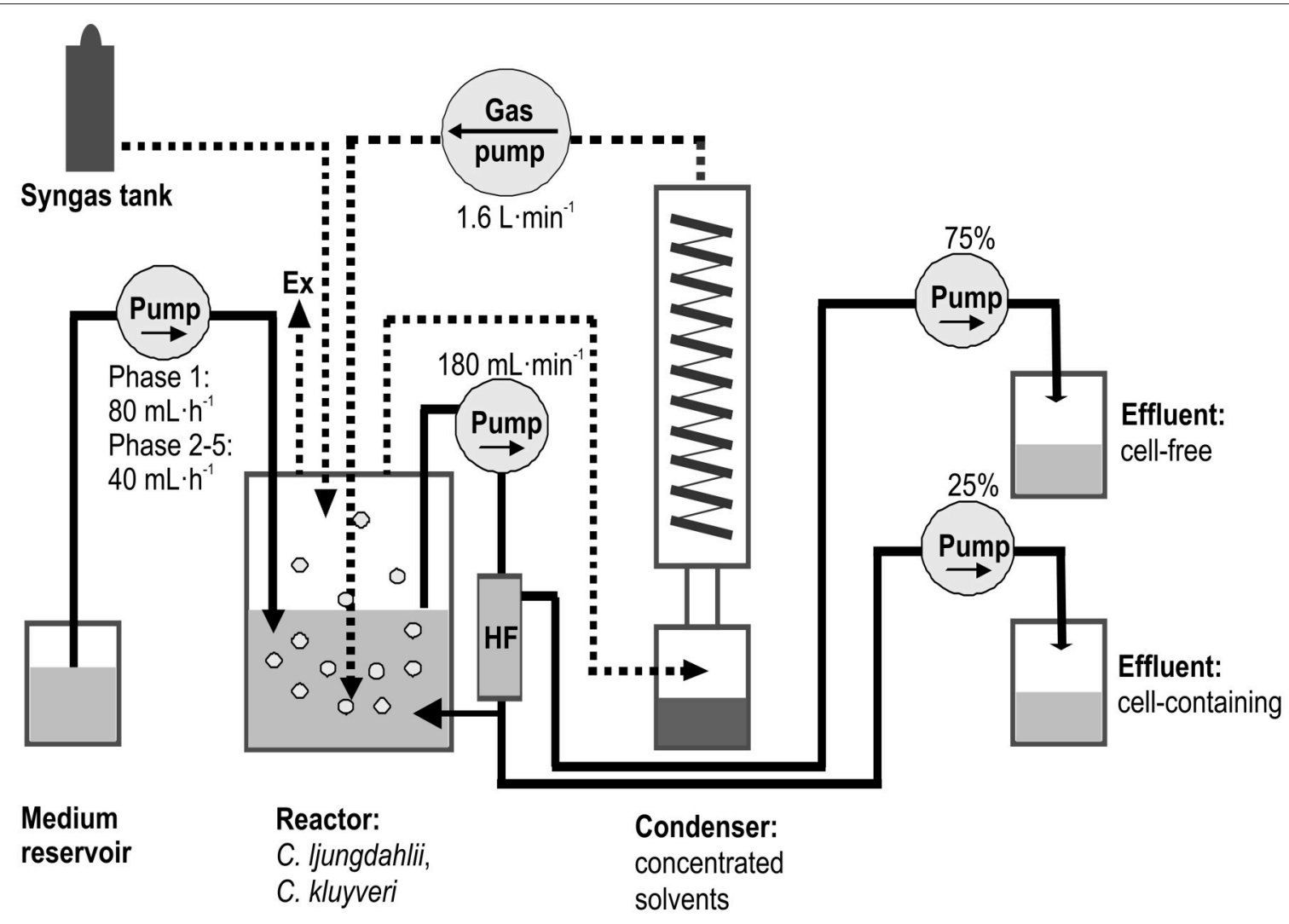

FIGURE 1 | Schematic view of the reactor. We operated a single-stage reactor with a co-culture of $C$. ljungdahlii and $C$. kluyveri that was fed continuously from a medium reservoir at a dilution rate of $80 \mathrm{~mL} \cdot \mathrm{h}^{-1}$ (Phase 1), and $40 \mathrm{~mL} \cdot \mathrm{h}^{-1}$ (Phase 2-5). The reactor was fed continuously with syngas $(60 \% \mathrm{CO}, 35 \% \mathrm{H} 2$, and $5 \%$ $\mathrm{CO}_{2}$ ) into the headspace. The gas was recirculated through a gas recycling loop into the reactor broth. A glass condenser unit was installed into the gas recycling loop to extract volatile compounds through gas stripping and condensation. The reactor broth was recirculated over a hollow fiber module (HF). $25 \%$ of the continuous reactor effluent consisted of cell-containing broth, while $75 \%$ of the reactor effluent was cell-free broth. Ex, exhaust gas outlet.

a microbubble-generating sparger (MoreFlavor, Concord, CA, USA) made of stainless steel with a pore size of $0.5 \mu \mathrm{m}$. We did not determine $\mathrm{K}_{L} \mathrm{a}$-values in this study, but with the high rate of gas recycling $\left(1.6 \mathrm{~L} \cdot \mathrm{min}^{-1}\right)$ and an agitation speed of 400 $\mathrm{rpm}, \mathrm{K}_{\mathrm{L}} \mathrm{a}$-values for gas-liquid mass transfer probably exceeded values that we had previously achieved (i.e., 373/h) (Martin et al., 2015), and it is unlikely that mass transfer was a limiting factor in this study. The liquid reactor broth was recirculated through a Cellflo polyethersulfone hollow fiber module with 500 $\mathrm{cm}^{2}$ membrane surface area and $0.2 \mu \mathrm{m}$ pore size (C22E-011$01 \mathrm{~N}$, Spectrum Laboratories, Inc., Rancho Dominguez, CA) at a flow rate of $180 \mathrm{~mL} \mathrm{~min}^{-1}$. The media feed rate was initially $80 \mathrm{~mL} \cdot \mathrm{h}^{-1}$ (until hour 1150), which was then reduced to 40 $\mathrm{mL} \cdot \mathrm{h}^{-1}$ (Figure 1). The peristaltic eight-channel media pump (ColeParmer, Court Vernon Hills, IL) for continuous operation was set-up in a way that $75 \%$ of the effluent consisted of cellfree filtrate coming from the cell-recycling module, and $25 \%$ of the effluent was cell-containing reactor broth (to remove dead cell material from the reactor). With respect to the retained cells, this setup resulted in a rate of cell withdrawal (bleed rate) of $1 / 4$ of the applied dilution rate. We cannot easily determine the actual specific growth rates for the two strains. However, during steady-state conditions the growth rates should be identical to the bleed rate, and therefore, $1 / 4$ of the media feed rate (i.e., $1 / 4 \cdot 0.08$ or $\left.1 / 4 \cdot 0.04 \cdot \mathrm{h}^{-1}\right)$, respectively. A reflux condenser made of pyrex glass was integrated into the gas recycling line to extract volatile products from the reactor broth by gas stripping and subsequent condensation. The condenser was kept at $1^{\circ} \mathrm{C}$ by a cooling water bath (Neslab RTE-111, Marshall Scientific, Hampton, NY).

\section{Analysis}

Samples were taken daily from the reactor and from the condensate $(N=1)$. The optical density (OD) was measured at $600 \mathrm{~nm}$ using a spectrophotometer (Milton Roy Spectronic 1201, Houston, TX). External pH measurements were performed with a $\mathrm{pH}$ probe (Orion Star, A329, Thermo Scientific, Waltham, $\mathrm{MA})$ to confirm and adjust the internal reactor $\mathrm{pH}$ control. Ethanol and acetate concentrations were obtained with an HPLC (Shimadzu Prominence UFLC, Shimadzu, Kyoto, Japan), which was equipped with an Aminex HPX-87H analytical column (Bio-Rad, Hercules, CA) at $65^{\circ} \mathrm{C}$ using $5 \mathrm{mM}$ sulfuric acid in water at a flow rate of $0.6 \mathrm{~mL} \cdot \mathrm{min}^{-1}$ as eluent. Concentrations of carboxylic acids (C4-C8) were measured using a gas chromatograph as previously described (Perez et al., 2013). Concentrations of higher alcohols (C4-C8) were measured using a gas chromatograph as previously described (Perez et al., 
2013), with an initial temperature hold for $3 \mathrm{~min}$ at $100^{\circ} \mathrm{C}$ and a temperature ramp of $40^{\circ} \mathrm{C} \cdot \mathrm{min}^{-1}$ to $220^{\circ} \mathrm{C}$, where the temperature was held for $5 \mathrm{~min}$.

Volumetric gas flow rates were measured with a custom-made in-line volumetric flow meter for the inlet gas, and a bubble flow meter for the outlet gas (Richter et al., 2013b). The gas pressure was measured using a digital pressure gauge (ColeParmer, Court Vernon Hills, IL) at the gas inlet and outlet of the reactor. Concentrations of $\mathrm{CO}, \mathrm{H}_{2}$, and $\mathrm{CO}_{2}$ were determined via gas chromatography as previously described (Perez et al., 2013). A phase-contrast microscope (Nikon Labophot, Nikon, Melville, NY) was used daily to monitor cell morphology. The volume of reactor effluent (cell-containing and cell-free) was measured to adjust the media flow rate when necessary. The reservoir bottles of the $2 \mathrm{M} \mathrm{KOH}$ and $2 \mathrm{M}$ acetic acid solutions were weighed to determine the amount of consumed base and acid.

Non-quantitative, strain-specific control PCRs were conducted to confirm the presence of both microbes in the reactor broth. EconoTaq PLUS GREEN 2X Master Mix (Lucigen, Middleton, WI) was used according to the manufacturer's recommendations in $50 \mu \mathrm{L}$ reaction volume. Primers specific for C. ljungdahlii (forward: 5'-AGTGCAGCGTATTCGTAA GG-3'; reverse: 5'-TAATGAGCCACGTCGTGTTG-3'; locus: 2172133-2172637), and for C. kluyveri (forward: 5'-CAAG CCTGGTAGTTGATACG-3'; reverse: $5^{\prime}$-TTAAAGGCCCTC TGTACTCC-3'; locus: 1822201-1822690) were used. MilliQ water, C. ljungdahlii genomic DNA, as well as pure cultures of C. ljungdahlii and C. kluyveri were used to demonstrate the strain-specificity (no cross reactions within the two species) for the primer pairs (Figure 2A). For sample preparation a sterile toothpick was used to transfer some biomass from a reactor cell pellet into $100 \mu \mathrm{L}$ of DNA-free water. The sample was boiled for $10 \mathrm{~min}$ before $1 \mu \mathrm{L}$ was used as template in the $50 \mu \mathrm{L}$ PCR reaction.

\section{RESULTS}

\section{n-Octanol (C8) Observed for First Time in a Syngas Fermentation System}

We operated a single-bioprocessing step with a co-culture for a period exceeding $2200 \mathrm{~h}$ (91 days; Figure 1). The reactor was continuously fed with a minimal nutrient broth solution and a procured syngas mixture of $60 \% \mathrm{CO}, 35 \% \mathrm{H}_{2}$, and $5 \%$ $\mathrm{CO}_{2}$. Periodic light microscopy monitoring revealed that the coculture consisted of two distinct morphologies, which may be assigned to C. ljungdahlii (thinner rods) and C. kluyveri (thicker rods, Figure 3). However, this is speculative since other factors could have affected the morphology of the two microbes and we cannot reliably differentiate with light microscopy. Therefore, we also performed a non-quantitative PCR analysis with speciesspecific primers. We did not find DNA amplicons for $C$. kluyveri for three samples after inoculation with C. kluyveri when the chain elongation activity (i.e., production of longer-chain carboxylates) was low (Figure 2). However, we found amplicons for samples that were taken at hours 1250, 1430, and 1850 of the operating period when MCCs were measured in the reactor (Figure 2B). We observed resilience of the co-culture with a

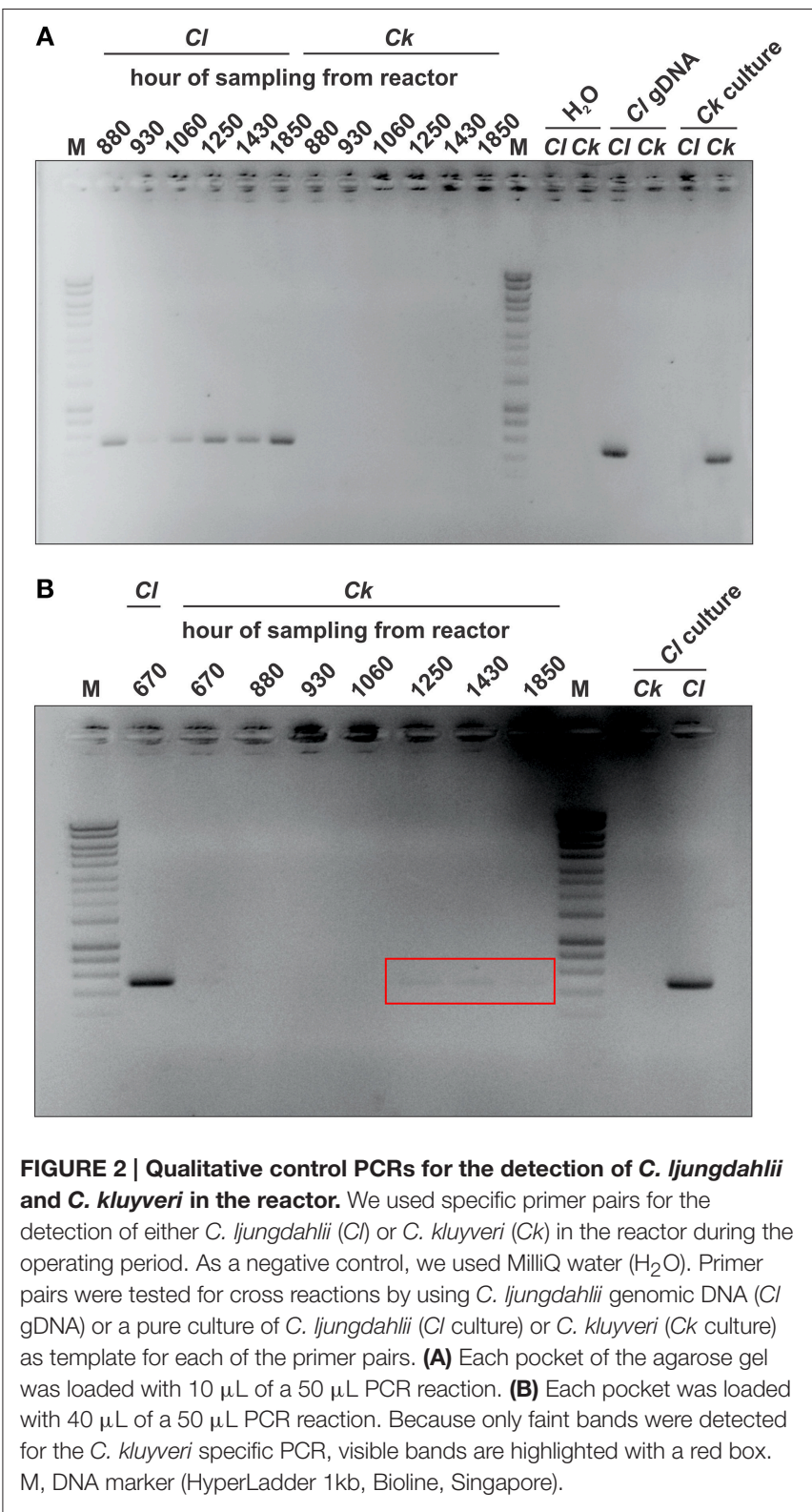

return to a dense cell population $\left(\mathrm{OD}_{600}\right.$ between 5 and 10$)$ after crashes in cell densities at hours 900 and 1600 (Figure 4A), which stemmed from an increase in the $\mathrm{pH}$ to 7 (Figure $4 \mathrm{~B}$ ). Even after these crashes, we observed chain elongation toward the end of the study, verifying that both C. ljungdahlii and $C$. kluyveri remained active in the co-culture. Together with the constant washout of $25 \%$ of bacterial cells in the effluent stream and the completely stirred conditions, we conclude that both strains showed sustainable growth and that they were resilient as a co-culture. Here, we operated one bioreactor and showed that the performance of the co-culture was stable during specific phases within the operating period. The results indicate that this process can be repeated. However, since we had several unexpected process perturbations, the exact profile might not be obtained again. Nevertheless, a well-functioning co-culture should be obtainable using the same process parameters. 


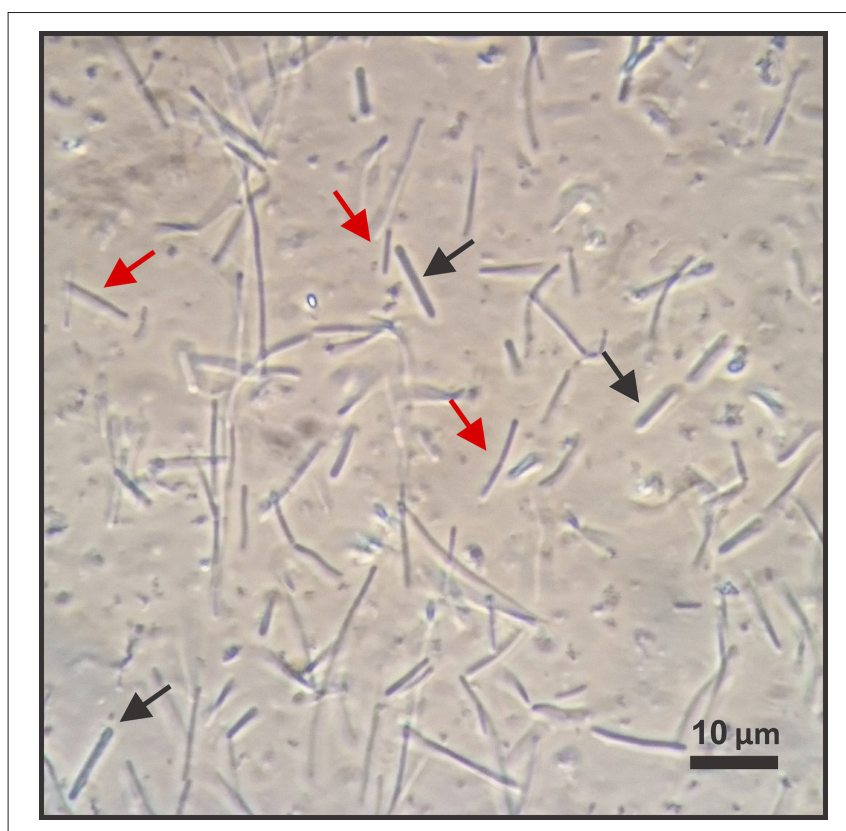

FIGURE 3 | Microscopy view of the co-culture with C. ljungdahlii and C. kluyveri. We used a phase-contrast microscope to periodically check the appearance of the co-culture. Black arrows point to cells of one morphology (thicker cells), while red arrows point to cells of another morphology (thinner cells). We observed this difference throughout the co-culture reactor run. However, it was not possible for us to clearly differentiate between $C$. ljungdahlii and C. Kluyveri by light microscopy.

The co-culture operation was divided into five distinct phases with fully continuous operating conditions (Phase 1-5). During Phase 1 and 2, the $\mathrm{pH}$ in the reactor was 6.0 with either a high dilution rate $\left(80 \mathrm{~mL} \cdot \mathrm{h}^{-1}\right)$ or a low dilution rate $\left(40 \mathrm{~mL} \cdot \mathrm{h}^{-1}\right)$, respectively. During Phase 3, the $\mathrm{pH}$ was 6.3; during Phase 4 , the $\mathrm{pH}$ was 6.4 ; and during Phase 5 , the $\mathrm{pH}$ was 5.7 ; with low dilution rates of $40 \mathrm{~mL} \mathrm{~h}^{-1}$ during Phases 3-5 (Figure 4B). During all five phases, we observed promising $\mathrm{CO}$ and $\mathrm{H}_{2}$ consumption rates with simultaneous $\mathrm{CO}_{2}$ production rates (Figure 4C), and ethanol and acetate production rates (Figure 4D). We report the average net production rates (Figure 4) and concentrations (Figure 5) for the liquid chemical species during the five phases in the reactor effluent, in the condensate of the stripping system, and for the combined system (reactor, strip, and combined in Table 1). To report the production rates, we utilize $\mathrm{mmol}$ carbon (C) as the unit rather than just mmol to compare fairly within this study and between studies, and to not underrepresent the production of longer-chain chemicals ( 1 mole of $n$-octanol is produced from at least 3 moles of ethanol $(3 \times C 2)$ plus 1 additional mole of ethanol or acetate (C2). Therefore, the volumetric production rates were expressed in mmol $\mathrm{C}$ per liter reactor volume per day (Table $\mathbf{1}$ and Figures $4 \mathrm{C}-\mathbf{G}$ ).

The highest average production rates for both longerchain alcohols and MCCs occurred during Phase 2 (Table 1). During this phase, the co-culture produced the following eight liquid chemicals with the combined, net volumetric production rates in parentheses, ordered from high to low average rates: acetate $\left(431 \mathrm{mmol} \mathrm{C} \cdot \mathrm{L}^{-1} \cdot \mathrm{d}^{-1}\right) ; n$-butyrate $(129 \mathrm{mmol}$
$\left.\mathrm{C} \cdot \mathrm{L}^{-1} \cdot \mathrm{d}^{-1}\right) ; n$-caproate $\left(70.0 \mathrm{mmol} \mathrm{C} \cdot \mathrm{L}^{-1} \cdot \mathrm{d}^{-1}\right)$; ethanol $(65.5$ mmol C.L $\left.\mathrm{L}^{-1} \cdot \mathrm{d}^{-1}\right) ; n$-butanol $\left(39.2 \mathrm{mmol} \mathrm{C} \cdot \mathrm{L}^{-1} \cdot \mathrm{d}^{-1}\right) ; n$-hexanol (31.7 mmol C. $\left.\mathrm{L}^{-1} \cdot \mathrm{d}^{-1}\right)$; 2,3-butanediol $\left(9.47 \mathrm{mmol} \mathrm{C} \cdot \mathrm{L}^{-1} \cdot \mathrm{d}^{-1}\right)$; and $n$-octanol $\left(0.045 \mathrm{mmol} \mathrm{C} \cdot \mathrm{L}^{-1} \cdot \mathrm{d}^{-1}\right)$ (SD in Table 1). During Phase 5, the highest average concentration of acetate $(244 \mathrm{mM})$ was measured in the reactor (Figures $\mathbf{5 A}, \mathbf{C}$ and Table $\mathbf{1}$ ), while the highest average concentrations of $n$-butyrate and $n$-caproate (30.7 and $11.0 \mathrm{mM}$, respectively) were found in the reactor during Phase 2 (Figures 5B,D and Table 1). Due to the concentrating effect of the gaseous stripping system for alcohols, the highest concentrations for ethanol, $n$-butanol, $n$-hexanol, and $n$-octanol $(345,56.8,46.3$, and $2.73 \mathrm{mM}$, respectively) were measured in the condensate compared to the reactor during different phases (Figures 5B,D and Table 1).

We achieved higher net production rates for all of these products in our continuous fermentation system compared to Diender et al. (2016) in their batch fermentation system with a different co-culture. Our production rates during Phase 2 were more than 2-fold higher for $n$-butanol and $n$-hexanol, more than 4-fold higher for $n$-caproate, and more than 9-fold higher for $n$ butyrate than theirs (Diender et al., 2016). As such, our system also achieved considerably higher production rates than with the reactor microbiome in a batch fermentation system of Ganigué et al. (2016). The chain elongation for these two studies had not observed longer-chain chemicals than C6. With the production of $n$-octanol this is, thus, the first study that observed C8 products within an anaerobic syngas fermentation system with wild-type strains. In the patent literature, a genetically modified CTB is described that can produce chemicals of up to C15 (farnesene) under anaerobic conditions (Chen et al., 2015). In addition, Hu et al. (2016) produced C16 and C18 products with genetically modified yeast, albeit under aerobic conditions in a separate bioprocessing step after the syngas fermentation step.

Between hour 1740 and 1860 of the operating period, we measured a concentration of up to $6 \mathrm{mM}$ of $n$-octanol in the condensate of the gas stripping system (Figure 5D), which is the highest concentration we measured. This resulted in a net average production rate of $0.125 \mathrm{mmol} \mathrm{C} \cdot \mathrm{L}^{-1} \cdot \mathrm{d}^{-1}$ for $n$-octanol (Figure 4G), and occurred during Phase 3 at a reactor $\mathrm{pH}$ of 6.3, which stimulated C. kluyveri to chain elongate with available ethanol and carboxylates. The higher $\mathrm{pH}$ of 6.3 compared to 6.0 is advantageous for C. kluyveri due to two reasons: (1) the growth conditions are more optimum (Barker and Taha, 1942); and (2) the concentrations of undissociated medium-chain carboxylic acids are lower (pKa of $\sim 4.9$ ), resulting in a lower microbial inhibition (Butkus et al., 2011). The resulting $n$-octanol production was achieved at a low selectivity and specificity (mol carbon in product per mol carbon in all other liquid products). During Phase 3 , the selectivity and specificity for $n$-octanol was $\sim 0.02$ and $0.03 \%$, respectively (Table 1 ). The production rate for $n$-octanol did not further increase when we increased the $\mathrm{pH}$ to 6.4 during Phase 4, most likely because of the lower C. ljungdahlii activity that provided less ethanol and acetate, decreasing the overall productivity of the process. We were able to observe the low production rates for $n$-octanol due to the accumulation effect in the condensate of the gaseous stripping system. The $n$ octanol concentrations in the reactor effluent remained below 


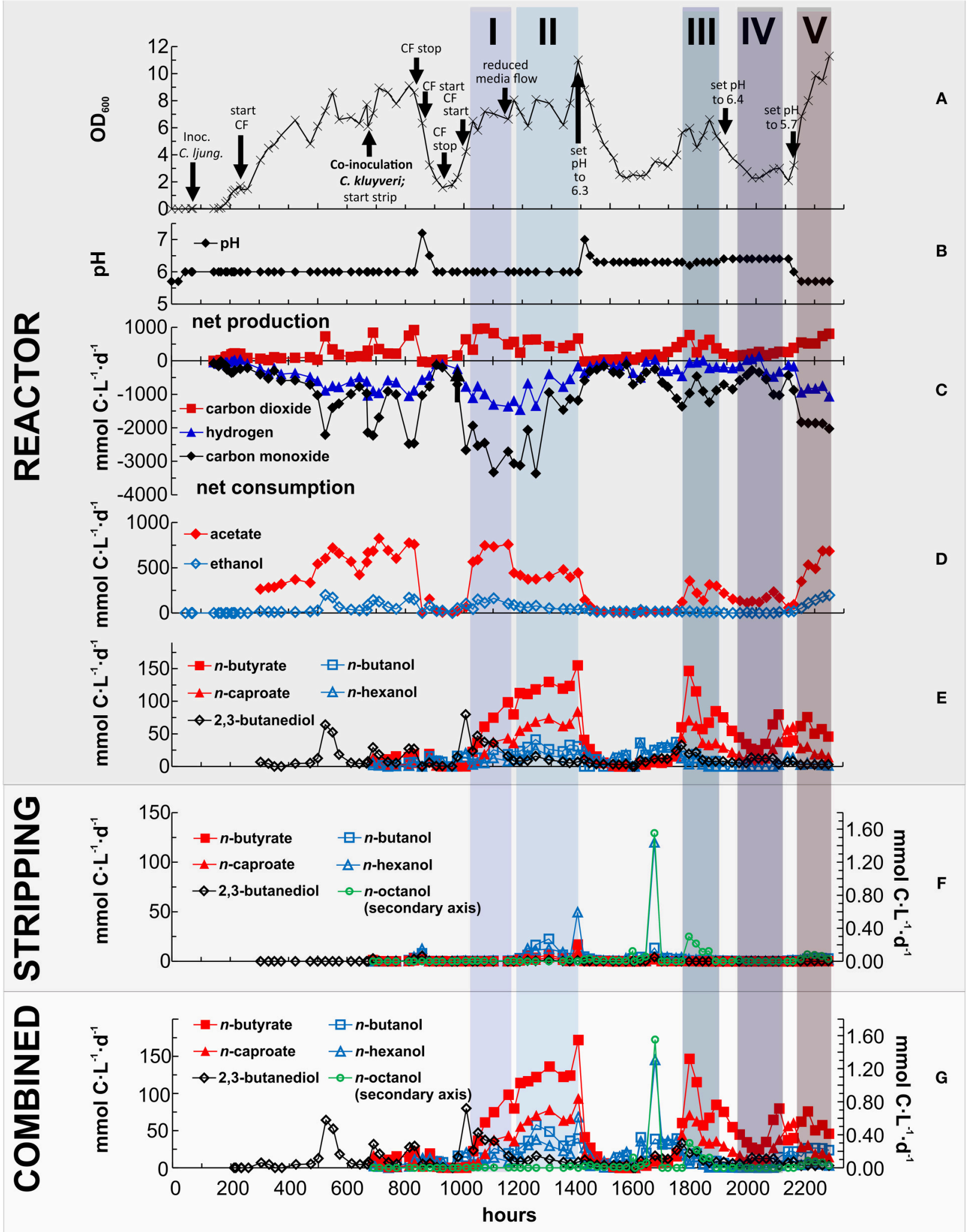

FIGURE 4 | Reactor performance during the continuous operation of $\sim 2250 \mathbf{~}$ (93 days). Data for one bioreactor run $(N=1$ per $D a y)$ for (A) growth $\left(\mathrm{OD}_{600}\right)$; (B) $\mathrm{pH}$; (C) net gas consumption (negative) or production (positive) rates for $\mathrm{CO}_{2}, \mathrm{H}_{2}$, and $\mathrm{CO}$ in $\mathrm{mmol} \mathrm{C} \cdot \mathrm{L}^{-1} \cdot \mathrm{d}^{-1}$; (D) net production rates for acetate and ethanol in (Continued) 


\section{FIGURE 4 | Continued}

the reactor in $\mathrm{mmol} \mathrm{C} \cdot \mathrm{L}^{-1} \cdot \mathrm{d}^{-1} ; \mathbf{( E )}$ net production rates for $n$-butyrate, $n$-caproate, 2,3 -butanediol, $n$-butanol, and $n$-hexanol in the reactor in $\mathrm{mmol} C \cdot \mathrm{L}^{-1} \cdot \mathrm{d}^{-1} ; \mathbf{( F )}$ net production rates for $n$-butyrate, $n$-caproate, 2,3 -butanediol, $n$-butanol, $n$-hexanol, and $n$-octanol in the stripping solution (condensate) in $\mathrm{mmol}^{\mathrm{C}} \cdot \mathrm{L}^{-1} \cdot \mathrm{d}^{-1} ; \mathbf{~ ( G ) ~}^{-}$ Combined net production rates (reactor + stripping solution) for $n$-butyrate, $n$-caproate, 2,3 -butanediol, $n$-butanol, $n$-hexanol, and $n$-octanol in mmol $\mathrm{C} \cdot \mathrm{L}^{-1} \cdot \mathrm{d}^{-1}$. The colored blocks labeled with I, II, III, IV, and V indicate the phases with stable reactor performance during continuous feeding, which we used for calculations. The high longer-chain alcohol production rates at hour 1650 were due to a clogging of the cell-recycling module, which led to an operation as fed-batch for $\sim 12 \mathrm{~h}$ and caused an accumulation of $400 \mathrm{~mL}$ reactor broth in the condenser due to foaming. The foaming was indicative of a high metabolic activity. Together with the fed-batch operation this may explain the non-sustainable and only temporary accumulation of longer-chain products, which led to the high production rate of $n$-hexanol and $n$-octanol. This, however, was a non-sustainable experimental event. After solving the operational issue (i.e., clogging of the cell-recycling module) and switching back to continuous mode operation the accumulated products were washed out of the reactor and the steady-state production rates during Phase 3 were reached as described in the text. CF, continuous feed.

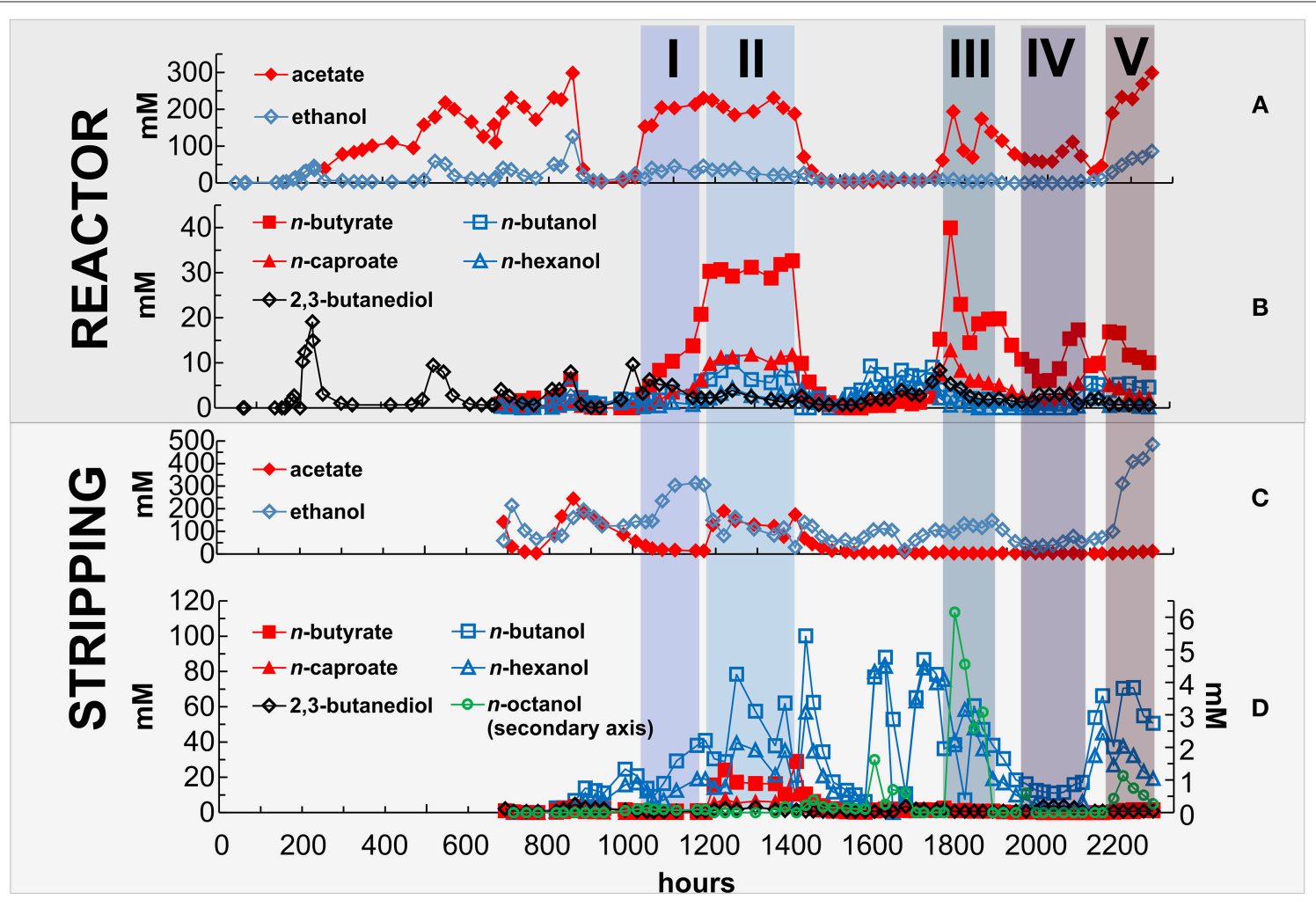

FIGURE 5 | Concentration of products in the reactor and in the stripping solution. Data for one bioreactor run ( $N=1$ per Day) for (A) net acetate and ethanol concentrations in the reactor in $\mathrm{mM}$; (B) net $n$-butyrate, $n$-caproate, 2,3-butanediol, $n$-butanol, and $n$-hexanol concentrations in the reactor in mM; (C) net acetate and ethanol concentrations in the stripping solution (condensate) in $\mathrm{mM}$; (D) net $n$-butyrate, $n$-caproate, 2,3-butanediol, $n$-butanol, $n$-hexanol, and $n$-octanol concentrations in the stripping solution (condensate) in $\mathrm{mM}$.

the detection limit for our GC method $(0.01 \mathrm{mM})$. In addition, the concentrations of $n$-caprylate in the reactor effluent and condensate remained below the detection limit $(0.04 \mathrm{mM})$.

\section{A Narrow, but Not Ideal, pH Spectrum Available for the Production of Longer-Chain Alcohols}

During Phase 2 at a $\mathrm{pH}$ of 6.0, the specificities (calculated on the basis of the production rates in $\mathrm{mmol} \mathrm{C} \cdot \mathrm{L}^{-1} \cdot \mathrm{d}^{-1}$ ) for ethanol, 2,3-butanediol, and acetate were 8.44, 1.22, and 55.5\%, respectively, with a total of $\sim 65 \%$ for the products from wildtype C. ljungdahlii (Table 1). Meanwhile, the specificities for $n$ butanol, $n$-hexanol, $n$-octanol, $n$-butyrate, and $n$-caproate were
$5.05,4.09,<1,16.7$, and $9.01 \%$, respectively (Table 1 ), with a total of $\sim 35 \%$ for the longer-chain chemicals after chain elongation with wild-type C. kluyveri. A simplified ratio of activity for C. ljungdahlii compared to C. kluyveri would be $1.9(65 / 35)$ when the biological reduction of MCCs is not included in the activity for C. ljungdahlii. However, this ratio is based on the net production rates, and because ethanol and acetate are removed during chain elongation, we would underestimate the importance of C. ljungdahlii. Next, we used the approach by Diender et al. (2016) to estimate the total volumetric production rates by including the production of intermediates (Table 2). Compared to the net volumetric production rates, the total volumetric production rates increased the ratio of activity for C. ljungdahlii compared to C. kluyveri from 1.9 to $2.2[(196+554) /(236+$ 
TABLE 1 | Balances for substrates and products during phases of steady-state.



Relevant concentrations and rates are given, selectivities and specificities were calculated from these data (with standard deviations in brackets, where applicable). Averages and standard deviations were obtained by analysis of all daily samples for each phase.

Comb, reactor and stripping combined; Conc, concentration; Phase 1, high flow rate of growth medium $\left(80 \mathrm{~mL} \cdot \mathrm{h}^{-1}\right), \mathrm{pH} 6.0, \mathrm{~N}=5$; Phase 2, low flow rate (40 $\left.\mathrm{mL} \cdot \mathrm{h}^{-1}\right)$, pH 6.0, $\mathrm{N}$ = 7; Phase 3, low flow rate $\left(40 \mathrm{~mL} \cdot \mathrm{h}^{-1}\right), \mathrm{pH}$ 6.3, $\mathrm{N}=6$; Phase 4, low flow rate $\left(40 \mathrm{~mL} \cdot \mathrm{h}^{-1}\right), \mathrm{pH} \mathrm{6.4,} \mathrm{N}=7$; Phase 5, low flow rate $\left(40 \mathrm{~mL} \cdot \mathrm{h}^{-1}\right), \mathrm{pH}$ 5.7, $\mathrm{N}=5 ; \mathrm{mol} \mathrm{C}, \mathrm{mol}$ carbon; prod, production; strip, stripping solution; \% selectivity calculated as mol carbon in respective product compared to mol carbon in substrate (CO) consumed; \% specificity calculated as mol carbon in specific product compared to mol carbon in all products (except $\mathrm{CO}_{2}$ which is not considered in this calculation). EtOH, ethanol; $\mathrm{ButOH}, \mathrm{n}$-butanol; HexOH, $n$-hexanol; OctOH, n-octanol; 2,3-BD, 2,3-butanediol; But, n-butyrate; Capro, n-caproate; Capry, n-caprylate.

102) in Table 2]. We also estimated that $2 / 3[(196-65.5) / 196$ in Tables 1, 2] of the total ethanol production was used to chain elongate with C. kluyveri.

During the operating period, we attempted to optimize the conditions for production of longer-chain alcohols and MCCs.
Initially, we had started the operating conditions of the reactor at a $\mathrm{pH}$ of 6.0. Based on the studies by Diender et al. (2016) and Ganigué et al. (2016), we knew that a discrepancy exists in optimum $\mathrm{pH}$ levels for ethanol production by CTB and growth by C. kluyveri. Since, ethanol production is a prerequisite for chain 
TABLE 2 | Total production rates in $\mathrm{mmol}$ carbon (C) $\cdot \mathrm{L}^{-1} \cdot \mathrm{d}^{-1}$ for acetate, ethanol, $n$-butyrate, and $n$-caproate (with standard deviations in brackets), calculated as the sum of combined production rates (see Table 1) of carbon chains that require each of the respective product as precursor.

\begin{tabular}{|c|c|c|}
\hline & Phase & Total production rate $\left(\mathrm{mmol} \mathrm{C} \cdot \mathrm{L}^{-1} \cdot \mathrm{d}^{-1}\right)$ \\
\hline \multirow[t]{5}{*}{ Acetate $_{\text {total }}$} & 1 & $812(129)$ \\
\hline & 2 & $554(43)$ \\
\hline & 3 & $284(99)$ \\
\hline & 4 & $168(46)$ \\
\hline & 5 & $715(201)$ \\
\hline \multirow[t]{5}{*}{ Ethanol $_{\text {total }}$} & 1 & $167(67)$ \\
\hline & 2 & $196(25)$ \\
\hline & 3 & $95(31)$ \\
\hline & 4 & $40(22)$ \\
\hline & 5 & $200(56)$ \\
\hline \multirow[t]{5}{*}{$n$-Butyrate total } & 1 & $93(50)$ \\
\hline & 2 & $236(43)$ \\
\hline & 3 & $136(49)$ \\
\hline & 4 & $62(32)$ \\
\hline & 5 & $100(17)$ \\
\hline \multirow[t]{5}{*}{$n$-Caproate ${ }_{\text {total }}$} & 1 & $30(21)$ \\
\hline & 2 & $102(29)$ \\
\hline & 3 & $54(20)$ \\
\hline & 4 & $18(11)$ \\
\hline & 5 & $27(7)$ \\
\hline
\end{tabular}

Acetate $_{\text {total }}=$ acetate $_{\text {Comb }}+$ ethanol $_{\text {comb }}+1 / 2 \times n$-butyrate $_{\text {comb }}+1 / 2 \times n$-butanol $_{\text {comb }}$ $+1 / 3 \times n$-caproate comb $+1 / 3 \times n$-hexanol comb $+1 / 4 \times n$-octanol comb $_{\text {. }}$.

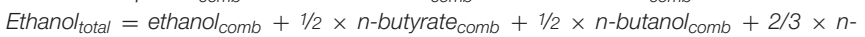
caproate $_{\text {comb }}+2 / 3 \times n$-hexanol comb $+3 / 4 \times n$-octanol comb. $_{\text {. }}$.

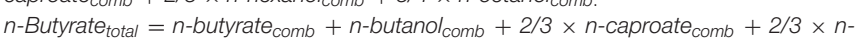
hexanol comb $+1 / 2 \times n$-octanol comb.

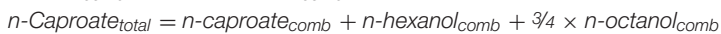

Acetate $_{\text {total }}$ is calculated as the maximum possible rate assuming the highest value of $1 \mathrm{~mol}$ acetate consumed for production of each mol of ethanol, n-butyrate, $n$-butanol, $n$-caproate, $n$-hexanol, and n-octanol. The real value is between 0 and $1 \mathrm{~mol}$ acetate for each mol of medium-chain product, and therefore the actual values for acetate $_{\text {total }}$ are likely lower than calculated here.

Ethanol total is calculated as the minimum required rate assuming 1,2, and 3 mol ethanol required per mol of 4-carbon, 6-carbon, and 8-carbon product, respectively. The actual values for ethanol total are likely higher than calculated here.

elongation by C. kluyveri, we set the $\mathrm{pH}$ at 6.0. During the startup phase with only $C$. ljungdahlii, we observed ethanol production rates of up to $170 \mathrm{mmol} \mathrm{C} \cdot \mathrm{L}^{-1} \cdot \mathrm{d}^{-1}$, but with acetate as the main product $\left(721 \mathrm{mmol} \mathrm{C} \cdot \mathrm{L}^{-1} \cdot \mathrm{d}^{-1}\right)$ and some 2,3-butanediol (52 mmol C. $\mathrm{L}^{-1} \cdot \mathrm{d}^{-1}$; Figures $\left.4 \mathrm{D}, \mathrm{E}\right)$. We inoculated C. kluyveri on hour 670 at this $\mathrm{pH}$ of 6.0 and observed some production of $n$-butanol, $n$-hexanol, $n$-butyrate, and $n$-caproate in addition to similar ethanol and acetate production rates (Figures $4 \mathrm{D}, \mathrm{E}$ ). From this, we concluded that we had established a co-culture of C. ljungdahlii and C. kluyveri, however, chain elongation was not very active. For that, the co-culture had to go through a $\mathrm{pH}$ perturbation.

Two operating problems at hour 850 and 1400 showed us that a $\mathrm{pH}$ of 7.0 or higher would have been a bad choice for sustainable chain elongation in the co-culture. First, a malfunction of the peristaltic pump for the continuous medium flow at hour 850 changed the reactor from a continuous to a batch system (Figure 4A). Because of the lack of an acid pumping system to control the upper $\mathrm{pH}$ limit, we observed an uncontrolled increase in the $\mathrm{pH}$ from 6.0 to 7.2. A similar $\mathrm{pH}$ increase had been observed by Diender et al. (2016) in batch fermentations with a co-culture of $C$. autoethanogenum and $C$. kluyveri. This neutral $\mathrm{pH}$ crashed the population of $C$. ljungdahlii because they cannot gain ATP via RNF complex/ATP synthase with a dissipated proton gradient, and thus cannot grow (Tanner et al., 1993). Without ethanol production from C. ljungdahlii, we observed an imminent collapse of the coculture (Figures 4C-F). After a period of batch conditions at a $\mathrm{pH}$ of 6.0, the C. ljungdahlii population recovered (Figure 4A), with sufficient syngas consumption (Figure 4C) after which the continuous operating conditions resumed (Phase 1). Second, a controlled $\mathrm{pH}$ increase to 6.3 at hour 1400 stimulated chain elongation so much that the $\mathrm{pH}$ again increased uncontrollably, resulting in the same negative outcome (Figures $4 \mathrm{C}-\mathrm{F}$ ).

For unknown reasons to us, however, the first $\mathrm{pH}$ perturbation seem to have given C. kluyveri an enduring advantage, resulting in considerably higher net production rates of longer-chain chemicals during Phase 1 at a pH of 6.0 (Figures 4E,G). After steady-state acetate production rates had been established during Phase 1 at a continuous medium flow rate of $80 \mathrm{~mL} \cdot \mathrm{h}^{-1}$, we reduced the flow rate to $40 \cdot \mathrm{mL} \mathrm{h}^{-1}$ during Phase 2 . This change in flow rate increased the average concentration of acetate from 186 to $205 \mathrm{mM}$ (Table 1), which we anticipated would increase solventogenesis in C. ljungdahlii (Richter et al., 2016), with a lower 2,3-butanediol production rate (Figure 4E). Even though this change resulted in lower net ethanol and acetate production rates (Figure 4D), the net production rates for all other observed products increased (Figure 4G). This means, that under these conditions the net activity for C. kluyveri was higher than during Phase 1, resulting in the highest observed chain elongation rates in this study.

Because only $2 / 3$ of the produced ethanol was removed during Phase 2 (Figure 4D), we concluded that the activity by $C$. ljungdahlii was not the rate limiting step in the co-culture at a $\mathrm{pH}$ of 6.0. Therefore, we increased the $\mathrm{pH}$ to 6.3 to boost the activity by $C$. kluyveri, while we anticipated that a further reduction in the activity by $C$. ljungdahlii was tolerable. Before increasing the $\mathrm{pH}$ during Phase 3, we installed an upper $\mathrm{pH}$ control with acetic acid to maintain a $\mathrm{pH}$ of 6.3 and to prevent a third $\mathrm{pH}$ perturbation. On average $\sim 0.3 \mathrm{~mL} \cdot \mathrm{d}^{-1}$ acetic acid was pumped after installing the upper $\mathrm{pH}$ control. This corresponds to only $0.6 \mathrm{mM} \cdot \mathrm{d}^{-1}$ acetic acid, and therefore was negligible in our calculations. We observed a stabilization of the co-culture with production rates slightly lower than during Phase 2 . As we had anticipated, the specificity for the net production of ethanol was reduced from 8.44 to $3.29 \%$, while the specificity for acetate, $n$-butyrate, and $n$-caproate was slightly increased compared to Phase 2 (Table 1). Unfortunately, the biological reduction of MCCs to longer-chain alcohols by C. ljungdahlii was also slowed due to the higher $\mathrm{pH}$ of 6.3. This resulted in a lower specificity of the longer-chain alcohols except for $n$-octanol (Table 1). We postulate that the decrease in biological reduction activity may 
be due to several reasons: (1) the growth of C. ljungdahlii is slower; (2) the concentrations of the undissociated mediumchain carboxylic acids, which are the substrates for the biological reduction, are lower (e.g., $3 \%$ at $\mathrm{pH} 6.3$ compared to $6 \%$ at $\mathrm{pH}$ 6.0 for acetic acid) (Richter et al., 2016); and (3) the lower COuptake by $C$. ljungdahlii may have increased the dissolved CO concentrations, reducing the C. kluyveri activity (Diender et al., 2016). However, the slightly higher $\mathrm{pH}$ of 6.3 compared to 6.0 increased the combined, net average production of $n$-octanol from 0.003 to $0.125 \mathrm{mmol} \mathrm{C} \cdot \mathrm{L}^{-1} \cdot \mathrm{d}^{-1}$ (Figures $4 \mathrm{~F}, \mathrm{G}$ ), resulting in a $\sim 10$-fold increase in the specificity for $n$-octanol to $0.03 \%$ during Phase 3 (Table 1).

We did find an increase in the relative chain elongation activity at the higher $\mathrm{pH}$ of 6.3. Besides the increased net production rates of the MCCs, a low net $\mathrm{H}_{2}$ consumption rate due to $\mathrm{H}_{2}$ production from chain elongation by $C$. kluyveri was also indicative of this increased activity in chain elongation (Figure 4C). Even though the net production rates of longerchain alcohols during Phase 3 were not as high as during Phase 2, the slightly higher $\mathrm{pH}$ of 6.3 compared to 6.0 , reduced the relative concentration of undissociated medium-chain carboxylic acids, which represent the volatile species, compared to dissociated MCCs. This resulted in a lower loss of carboxylate product from the reactor broth and a cleaner condensate with almost only higher-chain alcohols (Figure 5D). We did not measure esters (derived from a carboxylic acid and an alcohol) in the condensate, but we did observe a fruity smell of pineapple.

A further increase in the $\mathrm{pH}$ to 6.4 during Phase 4 was in agreement with the above finding for Phase 3 . The specificity for the net production rate of ethanol was further reduced from 3.26 to $1.25 \%$ (Table 1). In addition, the low ethanol availability likely decreased chain-elongation activity by $C$. kluyveri, which led to lower specificities for the net production rates of the medium-chain carboxylic acids (Table 1). This and further reduced biological reduction activity also decreased the specificities for the longer-chain alcohols (Table 1). Therefore, at a $\mathrm{pH}$ of 6.4 the low C. ljungdahlii activity is limiting the overall productivity of the process. To investigate the lower $\mathrm{pH}$ limit of the process, we decreased the $\mathrm{pH}$ again to 5.7 during Phase 5. At that $\mathrm{pH}$ we found the highest net ethanol production rate reported in this study $\left(144.7 \mathrm{mmol} \mathrm{C} \cdot \mathrm{L}^{-1} \cdot \mathrm{d}^{-1}\right)$ and the second highest net acetate production rate $\left(548 \mathrm{mmol} \mathrm{C} \cdot \mathrm{L}^{-1} \cdot \mathrm{d}^{-1}\right.$; Table 1). The specificity for the production rates of the longerchain alcohols was comparable to Phase 3 and 4 (Table 1). However, in this case not the low biological reduction activity by C. ljungdahlii was limiting, but the reduced chain-elongation activity by C. kluyveri, which led to low production rates of MCCs (Table 1).

\section{DISCUSSION}

\section{A Continuous Co-culture Bioprocessing Step Shows Resilience Over a Long Operating Period}

In this study, we have considerably enhanced the proof-ofconcept by Diender et al. (2016) to combine syngas fermentation, chain elongation, and biological reduction into one bioprocessing step with a defined co-culture of wild-type strains. Our bioprocessing system was continuously fed rather than operated as a batch, and continuous product extraction was included. Both wild-type strains in our co-culture remained active and showed resilience during an operating period of more than 1500 $\mathrm{h}$ (62 days). The result is a bioprocess that can recover $\mathrm{C} 1$ compounds into much higher value $\mathrm{C} 4-\mathrm{C} 8$ chemicals, including longer-chain alcohols such as $n$-hexanol and $n$-octanol. Of the small number of studied $\mathrm{pH}$-values, the optimum reactor $\mathrm{pH}$ was found to be 6.0 during which the production rates for either $n$-butanol and $n$-hexanol were $\sim 30-40 \mathrm{mmol} \mathrm{C} \cdot \mathrm{L}^{-1} \cdot \mathrm{d}^{-1}$, but at a relatively low specificity of $\sim 4-5 \%$ due the co-production of ethanol, 2,3-butanediol, acetate (main product), $n$-butyrate, $n$-caproate, and traces of $n$-octanol. With this, we verified a previously described $\mathrm{pH}$ discrepancy between currently available CTB and chain-elongating bacteria (Diender et al., 2016; Ganigué et al., 2016).

\section{Product Specificity May Remain Low Even after Optimization}

Therefore, regardless of what the best $\mathrm{pH}$ is for the maximum net production rates of longer-chain alcohols, the observed $\mathrm{pH}$ discrepancy for optimum function between C. ljundahlii and $C$. kluyveri makes this a less promising biotechnology production platform at this point in time. It is imperative to isolate a different chain-elongation bacterial strain with a growth optimum that is between 5 and 5.5. The operating performance at the lower $\mathrm{pH}$ would increase the total ethanol production rates by $C$. ljungdahlii. The matching $\mathrm{pH}$ optimum would then also lead to more equal activities of ethanol production and chain elongation, possibly yielding the promising production rates of longerchain alcohols that are necessary. A high production rate of such alcohols can only occur with a gaseous stripping system or a different product extraction system that maintains the concentration of these alcohols low enough to prevent product inhibition. This stripping system may need to be different from the current system when the goal is to mainly extract longerchain alcohols during a lower operating $\mathrm{pH}$ in the reactor.

But even when we acquire a co-culture with matching $\mathrm{pH}$ optima and install an ideal product extraction system, the specificities for the longer-chain alcohols may still remain low. This due to the competition for carboxylates as substrates between chain elongation and biological reduction in the single bioprocessing step that leads to a mixture of several longer-chain alcohols. In a system that performs exclusively chain elongation, the specificity for one single product can be much improved. For example, Agler et al. achieved $79 \%$ specificity for $n$-caproic acid (Agler et al., 2012). With chain elongation and biological reduction competing, we and others have observed mixtures of alcohols (Diender et al., 2016; Ganigué et al., 2016). The resulting low specificities raises the question whether we can ever achieve a truly promising chemical production platform within a single bioprocessing step for syngas fermentation with defined co-cultures of wild-type bacterial strains? On the other hand, a mixture of longer-chain alcohols may be suitable for certain application areas such as in the biofuel industry. In addition, an additional product separation step, such as distillation, after the stripping system could further separate the different alcohols. 


\section{Modeling and Comparison of Different Strategies for Bioprocessing Steps Necessary}

Alternatively, the combination of separate bioprocessing steps with a pure culture of CTB and chain-elongating bacteria in either mixed or pure cultures would allow for a more precise control. A syngas fermentation bioprocess as the first step (ethanol production), coupled to a chain-elongation bioprocess as the second step ( $n$-caproate production), and another syngas fermentation bioprocess as the third step ( $n$ hexanol production) - all three bioprocessing steps in separate reactors-may result in a considerably higher specificity for alcohols. Another possibility is to couple two bioprocessing steps within a recycle loop to perform ethanol production and biological reduction of MCCs in the same bioprocessing step with syngas.

A comparison of the three strategies (single bioprocessing step, three separate bioprocessing steps, two separate bioprocessing steps combined as a recycling loop) by modeling of the product spectrum under different process conditions could be used to get a better understanding. Here, we provided a proof-of-concept for the resilience and functionality of a single bioprocessing step with a co-culture of pure strains in continuous operation mode. Which of the three strategies will eventually be the best choice as a bioproduction platform at an industrial scale cannot be answered at this point in time

\section{REFERENCES}

Agler, M. T., Spirito, C. M., Usack, J. G., Werner, J. J., and Angenent, L. T. (2012). Chain elongation with reactor microbiomes: upgrading dilute ethanol to medium-chain carboxylates. Energy Environ. Sci. 5, 8189-8192. doi: 10.1039/c2ee22101b

Agler, M. T., Spirito, C. M., Usack, J. G., Werner, J. J., and Angenent, L. T. (2014). Development of a highly specific and productive process for $n$-caproic acid production: applying lessons from methanogenic microbiomes. Water Sci. Technol. 69, 62-68. doi: 10.2166/wst.2013.549

Angenent, L. T., Richter, H., Buckel, W., Spirito, C. M., Steinbusch, K. J., Plugge, C. M., et al. (2016). Chain elongation with reactor microbiomes: open-culture biotechnology to produce biochemicals. Environ. Sci. Technol. 50, 2796-2810. doi: 10.1021/acs.est.5b04847

Banerjee, A., Leang, C., Ueki, T., Nevin, K. P., and Lovley, D. R. (2014). Lactoseinducible system for metabolic engineering of Clostridium ljungdahlii. Appl. Environ. Microbiol. 80, 2410-2416. doi: 10.1128/AEM.03666-13

Barker, H. A., and Taha, S. M. (1942). Clostridium kluyverii, an organism concerned in the formation of caproic acid from ethyl alcohol. J. Bacteriol. 43, 347-363.

Bruant, G., Lévesque, M.-J., Peter, C., Guiot, S. R., and Masson, L. (2010). Genomic analysis of carbon monoxide utilization and butanol production by Clostridium carboxidivorans Strain P7T. PLoS ONE 5:e13033. doi: 10.1371/journal.pone.0013033

Butkus, M. A., Hughes, K. T., Bowman, D. D., Liotta, J. L., Jenkins, M. B., and Labare, M. P. (2011). Inactivation of Ascaris suum by short-chain fatty acids. Appl. Environ. Microbiol. 77, 363-366. doi: 10.1128/AEM.01675-10

Chen, W. Y., Liew, F., and Koepke, M. (2015). Microbial Fermentation for the Production of Terpenes. US 14/656, 827.

Daniell, J., Nagaraju, S., Burton, F., Köpke, M., and Simpson, S. D. (2016). "Low-carbon fuel and chemical production by anaerobic gas fermentation," in Advances in Biochemcal Engineering/Biotechnology (Berlin; Heidelberg: Springer), $1-29$. and more applied research is necessary. The choice may also be depending on whether a pure product or a mixture of long-chain alcohols is desired.

\section{AUTHOR CONTRIBUTIONS}

$\mathrm{HR}, \mathrm{BM}, \mathrm{MD}, \mathrm{DS}$, and LA designed the study; HR and BM performed the research and sample analysis; $\mathrm{HR}$ and $\mathrm{BM}$ analyzed the data, and $\mathrm{HR}, \mathrm{BM}, \mathrm{MD}, \mathrm{DS}$, and LA wrote the manuscript.

\section{FUNDING}

This work was supported by the NSF SusChEM Program (Award \#1336186) and by the U.S. Army Research Laboratory and the U.S. Army Research Office (Contract/Grant number W911NF12-1-0555), which were awarded to LA. In addition, BM was funded through a postdoctoral research fellowship from the German Research Foundation (DFG, MO2933/1-1). Research of MD and DS is financed by the European Research Council (ERC Grant Agreement 323009) and the Netherlands Ministry of Education, Culture and Science (Gravitation grant 024.002.002).

\section{ACKNOWLEDGMENTS}

We like to thank Sylvia Gildemyn for helpful discussions.

Diender, M., Stams, A. J., and Sousa, D. Z. (2016). Production of medium-chain fatty acids and higher alcohols by a synthetic co-culture grown on carbon monoxide or syngas. Biotechnol. Biofuels. 9, 1. doi: 10.1186/s13068-016-0495-0

Dry, M. E. (2002). The Fischer-Tropsch process: 1950-2000. Catal. Today 71, 227-241. doi: 10.1016/S0920-5861(01)00453-9

Dürre, P. (2016). Butanol formation from gaseous substrates. FEMS Microbiol. Lett. 363:fnw040. doi: 10.1093/femsle/fnw040

Ganigué, R., Sánchez-Paredes, P., Bañeras, L., and Colprim, J. (2016). Low fermentation $\mathrm{pH}$ is a trigger to alcohol production, but a killer to chain elongation. Front. Microbiol. 7:702. doi: 10.3389/fmicb.2016.00702

Grootscholten, T. I. M., Steinbusch, K. J. J., Hamelers, H. V. M., and Buisman, C. J. N. (2013). Improving medium chain fatty acid productivity using chain elongation by reducing the hydraulic retention time in an upflow anaerobic filter. Bioresour. Technol. 136, 735-738. doi: 10.1016/j.biortech.2013.02.114

Hanselmann, K. W. (1991). Microbial energetics applied to waste repositories. Cell. Mol. Life Sci. 47, 645-687. doi: 10.1007/BF01958816

Hu, P., Chakraborty, S., Kumar, A., Woolston, B., Liu, H., Emerson, D., et al. (2016). Integrated bioprocess for conversion of gaseous substrates to liquids. Proc. Natl. Acad. Sci. U.S.A. doi: 10.1073/pnas.1516867113

Huang, H., Chai, C., Li, N., Rowe, P., Minton, N. P., Yang, S., et al. (2016). CRISPR/Cas9-based efficient genome editing in Clostridium ljungdahlii, an autotrophic gas-fermenting bacterium. ACS Synth. Biol. doi: 10.1021/acssynbio.6b00044. [Epub ahead of print].

Kenealy, W. R., and Waselefsky, D. M. (1985). Studies on the substrate range of Clostridium kluyveri; the use of propanol and succinate. Arch. Microbiol. 141, 187-194. doi: 10.1007/BF00408056

Kleerebezem, R., and Van Loosdrecht, M. C. M. (2010). A generalized method for thermodynamic state analysis of environmental systems. Crit. Rev. Environ. Sci. Technol. 40, 1-54. doi: 10.1080/10643380802000974

Köpke, M., Held, C., Hujer, S., Liesegang, H., Wiezer, A., Wollherr, A., et al. (2010). Clostridium ljungdahlii represents a microbial production platform based on syngas. Proc. Natl. Acad. Sci. U.S.A. 107, 13087-13092. doi: $10.1073 /$ pnas. 1004716107 
Köpke, M., Simpson, S., Liew, F., and Chen, W. (2012). Fermentation Process for Producing Isopropanol Using a Recombinant Microorganism. US 2012/0252083A1

Kucek, L. A., Spirito, C. M., and Angenent, L. T. (2016). High n-caprylate productivities and specificities from dilute ethanol and acetate: chain elongation with microbiomes to upgrade products from syngas fermentation. Energy Environ. Sci. 9, 3482-3494. doi: 10.1039/c6ee01487a

Liew, F., Martin, M. E., Tappel, R. C., Heijstra, B. D., Mihalcea, C., and Köpke, M. (2016). Gas fermentation - a flexible platform for commercial scale production of low carbon fuels and chemicals from waste and renewable feedstocks. Front. Microbiol. 7:694. doi: 10.3389/fmicb.2016.00694

Liew, F. M., Köpke, M., and Simpson, S. D. (2013). "Gas fermentation for commercial biofuels production," in Liquid, Gaseous and Solid Biofuels Conversion Techniques, ed Z. Fang (INTECH Open Access Publisher). doi: $10.5772 / 52164$

Martin, M. E., Richter, H., Saha, S., and Angenent, L. T. (2015). Traits of selected Clostridium strains for syngas fermentation to ethanol. Biotechnol. Bioeng. 113, 531-539. doi: 10.1002/bit.25827

Mock, J., Zheng, Y., Mueller, A. P., Ly, S., Tran, L., Segovia, S., et al. (2015). Energy conservation associated with ethanol formation from $\mathrm{H}_{2}$ and $\mathrm{CO}_{2}$ in Clostridium autoethanogenum involving electron bifurcation. J. Bacteriol. 197, 2965-2980. doi: 10.1128/JB.00399-15

Mohammadi, M., Najafpour, G. D., Younesi, H., Lahijani, P., Uzir, M. H., and Mohamed, A. R. (2011). Bioconversion of synthesis gas to second generation biofuels: a review. Renew. Sust. Energ. Rev. 15, 4255-4273. doi: 10.1016/j.rser.2011.07.124

Molitor, B., Richter, H., Martin, M. E., Jensen, R. O., Juminaga, A., Mihalcea, C., et al. (2016). Carbon recovery by fermentation of CO-rich off gasesTurning steel mills into biorefineries. Bioresour. Technol. 215, 386-396. doi: 10.1016/j.biortech.2016.03.094

Munasinghe, P. C., and Khanal, S. K. (2010). Biomass-derived syngas fermentation into biofuels: Opportunities and challenges. Bioresour. Technol. 101, 5013-5022. doi: 10.1016/j.biortech.2009.12.098

Oswald, F., Dörsam, S., Veith, N., Zwick, M., Neumann, A., Ochsenreither, K., et al. (2016). Sequential mixed cultures: from syngas to malic acid. Front. Microbiol. 7:891. doi: 10.3389/fmicb.2016.00891

Perez, J. M., Richter, H., Loftus, S. E., and Angenent, L. T. (2013). Biocatalytic reduction of short-chain carboxylic acids into their corresponding alcohols with syngas fermentation. Biotechnol. Bioeng. 110, 1066-1077. doi: 10.1002/bit. 24786

Ramió-Pujol, S., Ganigu,é, R., Bañeras, L., and Colprim, J. (2015). Incubation at $25^{\circ} \mathrm{C}$ prevents acid crash and enhances alcohol production in Clostridium carboxidivorans P7. Bioresour. Technol. 192, 296-303. doi: 10.1016/j.biortech.2015.05.077

Richter, H., Loftus, S. E., and Angenent, L. T. (2013a). Integrating syngas fermentation with the carboxylate platform and yeast fermentation to reduce medium cost and improve biofuel productivity. Environ. Technol. 34, 1983-1994. doi: 10.1080/09593330.2013.826255

Richter, H., Martin, M., and Angenent, L. (2013b). A two-stage continuous fermentation system for conversion of syngas into ethanol. Energies 6, 3987-4000. doi: 10.3390/en6083987
Richter, H., Molitor, B., Wei, H., Chen, W., Aristilde, L., and Angenent, L. T. (2016). Ethanol production in syngas-fermenting Clostridium ljungdahlii is controlled by thermodynamics rather than by enzyme expression. Energy Environ. Sci. 9, 2392-2399. doi: 10.1039/C6EE01108J

Seedorf, H., Fricke, W. F., Veith, B., Brüggemann, H., Liesegang, H., Strittmatter, A., et al. (2008). The genome of Clostridium kluyveri, a strict anaerobe with unique metabolic features. Proc. Natl. Acad. Sci. U.S.A. 105, 2128-2133. doi: 10.1073/pnas.0711093105

Spirito, C. M., Richter, H., Rabaey, K., Stams, A. J., and Angenent, L. T. (2014). Chain elongation in anaerobic reactor microbiomes to recover resources from waste. Curr. Opin. Biotechnol. 27C, 115-122. doi: 10.1016/j.copbio.2014.01.003

Tanner, R. S., Miller, L. M., and Yang, D. (1993). Clostridium ljungdahlii sp. nov., an acetogenic species in clostridial rRNA homology group I. Int. J. Syst. Bacteriol. 43, 232-236. doi: 10.1099/00207713-43-2-232

Thauer, R. K., Jungermann, K., Henninger, H., Wenning, J., and Decker, K. (1968). The energy metabolism of Clostridium kluyveri. Eur. J. Biochem. 4, 173-180. doi: 10.1111/j.1432-1033.1968.tb00189.x

Ueki, T., Nevin, K. P., Woodard, T. L., and Lovley, D. R. (2014). Converting carbon dioxide to butyrate with an engineered strain of Clostridium ljungdahlii. MBio 5, e01636-e01614. doi: 10.1128/mBio.01636-14

Vasudevan, D., Richter, H., and Angenent, L. T. (2014). Upgrading dilute ethanol from syngas fermentation to $n$-caproate with reactor microbiomes. Bioresour. Technol. 151, 378-382. doi: 10.1016/j.biortech.2013.09.105

Walker, D. J. F., and Köpke, M. (2015). Method of Producing a Recombinant Microorganism. US 14/608,132.

Wang, Y., Zhang, Z.-T., Seo, S.-O., Choi, K., Lu, T., Jin, Y.-S., et al. (2015). Markerless chromosomal gene deletion in Clostridium beijerinckii using CRISPR/Cas9 system. J. Biotechnol. 200, 1-5. doi: 10.1016/j.jbiotec.2015. 02.005

Weimer, P. J., and Stevenson, D. M. (2012). Isolation, characterization, and quantification of Clostridium kluyveri from the bovine rumen. Appl. Microbiol. Biotechnol. 94, 461-466. doi: 10.1007/s00253-011-3 751-z

Worden, R., Grethlein, A., Jain, M., and Datta, R. (1991). Production of butanol and ethanol from synthesis gas via fermentation. Fuel 70, 615-619. doi: 10.1016/0016-2361(91)90175-A

Xu, T., Li, Y., Shi, Z., Hemme, C. L., Li, Y., Zhu, Y., et al. (2015). Efficient genome editing in Clostridium cellulolyticum via CRISPR-Cas9 nickase. Appl. Environ. Microbiol. 81, 4423-4431. doi: 10.1128/AEM.00873-15

Conflict of Interest Statement: The authors declare that the research was conducted in the absence of any commercial or financial relationships that could be construed as a potential conflict of interest.

Copyright (C) 2016 Richter, Molitor, Diender, Sousa and Angenent. This is an openaccess article distributed under the terms of the Creative Commons Attribution License (CC BY). The use, distribution or reproduction in other forums is permitted, provided the original author(s) or licensor are credited and that the original publication in this journal is cited, in accordance with accepted academic practice. No use, distribution or reproduction is permitted which does not comply with these terms. 